\title{
The Research on the Path of Rural Bank's Transformation Based on Bourdieu*'s Practice Theory: A Case Study of Wuwei Rural Bank in China
}

\author{
Huifen Wang', Meilin Chen" ${ }^{1 \#, ~ B i n ~ Z h e n g 2 ~}$ \\ ${ }^{1}$ Management School, Jinan University, Guangzhou, China \\ ${ }^{2}$ Wuwei Rural Bank, Wuwei, China \\ Email: twhf@163.com,\#MerlyChen@126.com, zhengbin69@sina.com
}

How to cite this paper: Wang, H.F., Chen, M.L. and Zheng, B. (2017) The Research on the Path of Rural Bank's Transformation Based on Bourdieu's Practice Theory: A Case Study of Wuwei Rural Bank in China. Journal of Service Science and Management, 10, 319-329.

https://doi.org/10.4236/jssm.2017.103025

Received: October 21, 2016

Accepted: June 23, 2017

Published: June 26, 2017

Copyright $\odot 2017$ by authors and Scientific Research Publishing Inc. This work is licensed under the Creative Commons Attribution International License (CC BY 4.0).

http://creativecommons.org/licenses/by/4.0/

\begin{abstract}
More than 1000 Chinese rural banks' asset size exceeded trillion in 2015, but they have problems in low operating efficiency, information asymmetry between rural banks and villagers, poor public trust, insufficient absorption capacity and low social awareness. Should rural banks still stick to the rural areas? What's the way to develop the rural financial market at present? With Bourdieu's practice theory, this paper analyses the transformation practice of "the Bank-Government miaxture" model of the Wuwei Rural Bank in China. The Wuwei Rural Bank plants habitus, field and capital (mainly symbolic capital and social capital) into the transformation practice. This paper benefits from a particular ethnography enriched by the oral reviews and engaged observations in two years of fieldwork. Thirty-four depth interviews were conducted, involving the Wuwei Rural Bank's staffs, the mayors of 21 towns, convenience stores staffs, school principals, clinic employees and many villagers. Analysing the capital and changing the habitus of the villagers makes the transformation successful. It gives a new perspective for the path of rural bank's transformation.
\end{abstract}

\section{Keywords}

Bourdieu, Symbolic Capital, Social Capital, Habitus,

"The Bank-Government Mixture" Model 


\section{Introduction}

Aimed at the problems that the economic subjects (farmers, small and micro enterprises) have difficulties in financing, the reform of rural finance in China has never stopped [1]. There are also a large number of financial services blank, so the rural banks emerge as a new type of rural financial institutions. The establishment of rural banks must be approved by the Chinese Banking Regulatory Commission in accordance with the law. The rural banks have independent management under the principle of security, liquidity and profitability, self financing and self binding, and can carry out business in accordance with the law, not by any unit and individual interference. They can do the business of deposits and loans, settlement, bills, lending and other general commercial banking business, and also can agent policy banks, securities companies, insurance companies and other financial institutions do all kinds of other business [2]. In recent years, rural banks developed rapidly (see the Table 1 and the Figure 1 ). The rapid development of rural banks alleviates the problems of the current rural financial institutions, such as too few outlets, too low service efficiency, relative single business, improves the status of financial services in rural areas, and they play an important role for rural economic development in China. But they are also faced with a variety of problems and defects, low operating efficiency [3], information asymmetry between rural banks and villagers [4], poor public trust [5], insufficient absorption capacity, low social awareness [6].

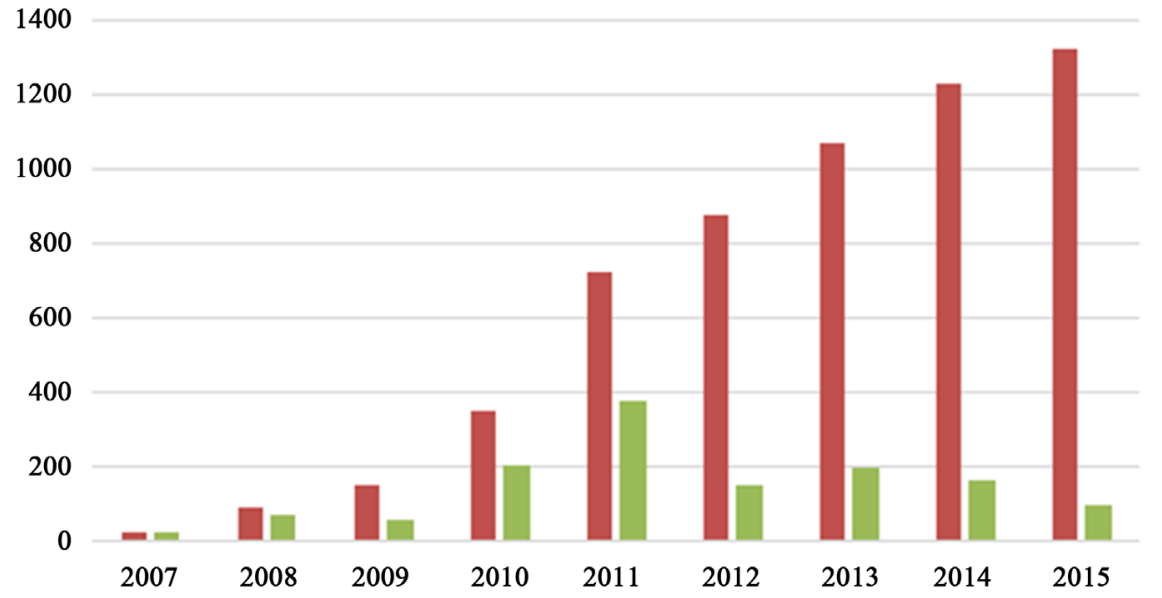

the Total Number of Rural Banks the Increment of Rural Banks

Figure 1. The number and growth of rural banks.

Table 1. The number and growth of rural banks during the years of 2007 to 2015.

\begin{tabular}{cccccccccc}
\hline Year & 2007 & 2008 & 2009 & 2010 & 2011 & 2012 & 2013 & 2014 & 2015 \\
\hline $\begin{array}{c}\text { the total number } \\
\text { of rural banks }\end{array}$ & 19 & 91 & 148 & 349 & 726 & 876 & 1071 & 1233 & 1327 \\
$\begin{array}{c}\text { the increment } \\
\text { of rural banks }\end{array}$ & 19 & 72 & 57 & 201 & 377 & 150 & 195 & 162 & 94 \\
\hline
\end{tabular}


So the rural banks need to transform to change the present situation. However, the traditional research is only limited to the financial sector or the field of management, without considering the interaction between the rural society and the rural banks, so the transformation of the proposed strategy is "treat the head when the headaches, treat the foot when the foot hurts", it cannot solve the fundamental problem. These studies are based on the philosophical thinking of the dichotomy, seeing the rural banks and other actors as independent, so that they cannot get to the root of the problems.

This research jumps out of the single management research, introducing the sociologist Pierre Bourdieu's practice theory into the field of management. We use its relational philosophical thinking and the key concepts to framework the rural banks' transformation, and use the ethnographic and fieldwork method to observe the entanglement between economic capital, cultural capital, social capital and symbolic capital of different actors, and the change of their habitus in the field of transformation, and the build of different relations.

Our goal in this paper is to contribute to the path of rural bank's transformation by introducing Bourdieu's practice theory. We explore a unique transformation path through the empirical case of Wuwei Rural Bank in China. Through the case, we will make clear explanation about how villagers' habitus change and how the rural bank makes full use of the symbolic capital and social capital in order to develop. And the operational mechanisms of Wuwei Rural Bank will provide a new perspective for other rural banks who want to transform.

\section{Bourdieu's Theory}

\subsection{Why Bourdieu?}

In recent years, Bourdieu's practice theory has served as a provocation in the field of organization studies, encouraging debate about the logic of practice [7] [8] [9] [10]. Our purpose in engaging with it has been to call for an open process of theoretical and practical exploration that in the longer term will support the development of such organization studies, especially the transformation of rural banks. Our existing rural bank transformation research has generated multiple theories, paths and findings [11]. These have been both insightful and useful. However, they looked rural bank and villagers or government as relatively stable, singular, and separable. This is a typical dichotomy thinking. Given the current evidence of unprecedented shifts associated with technologies in practice-automated trading, mobile platforms, and social media, to name just a few-it may be more germane to develop ways of thinking and working that allow us to investigate a reality that is dynamic, multiple, and entangled [12]. This is a kind of relational thinking. It has jumped out of the traditional confrontation between subjective and objective, micro and macro, individual and society, people and objects. And Bourdieu's practice logic provides us with such a theoretical guidance.

\subsection{What Are the Key Concepts?}

Bourdieu's ideas constitute a practice theory based on his "relational thinking" 
[13]. The key concepts of it are habitus, capital and field, and Bourdieu summarizes their relationship as follows: Practice $=($ habitus $\times$ capital $)+$ field [14] . Thus we can have a better understanding about the relations among the three main concepts, and we can depict the structural logic among them (see the Figure 2).

Habitus is one of the core concepts of Bourdieu's practice theory. It is a set of acquired patterns of meanings, beliefs, behaviors and tastes [15]. According to Bourdieu, it is produced in such a phenomenon that agents structure their world, and the embodied schemas are constituted throughout history and are acquired by the agents. Then they (re) create these schemas through their practical actions because they are imposed/inscribed on the body, and have never passed through their consciousness [16]. The habitus of people who live in the same context and share a similar social class will be homologous.

Habitus is a way of conceptualizing how social structures influence practice without reifying those structures or falling into the traps of voluntarism, determinism, subjectivism, and objectivism [17]. Habitus tends to generate practices that are positively sanctioned as reasonable and commonsense. Such practices are likely, Bourdieu argues, to be adjusted to the objective conditions of existence. Thus, given a set of conditions, habitus affords an actor some thoughts and behaviors and not others, making those thoughts and behaviors seem more appropriate, attractive, and authentic than others.

As for Bourdieu, habitus refers to the total effect of the internalization of social behavior in personal consciousness in the specific historical conditions, especially internal and symbolic structured results of the individual consciousness in the education system of a particular society. It is a priori reflection model, and is the individual and group specific behavior style settled into "survival mentality" and long-term repeated. It is the life experience constituting mentality structure, and is the nature of thinking system and behavior modes, with lasting effect. Once these experience factors from long-term practice experience the precipitation of a certain historical period, and internalize into the group and

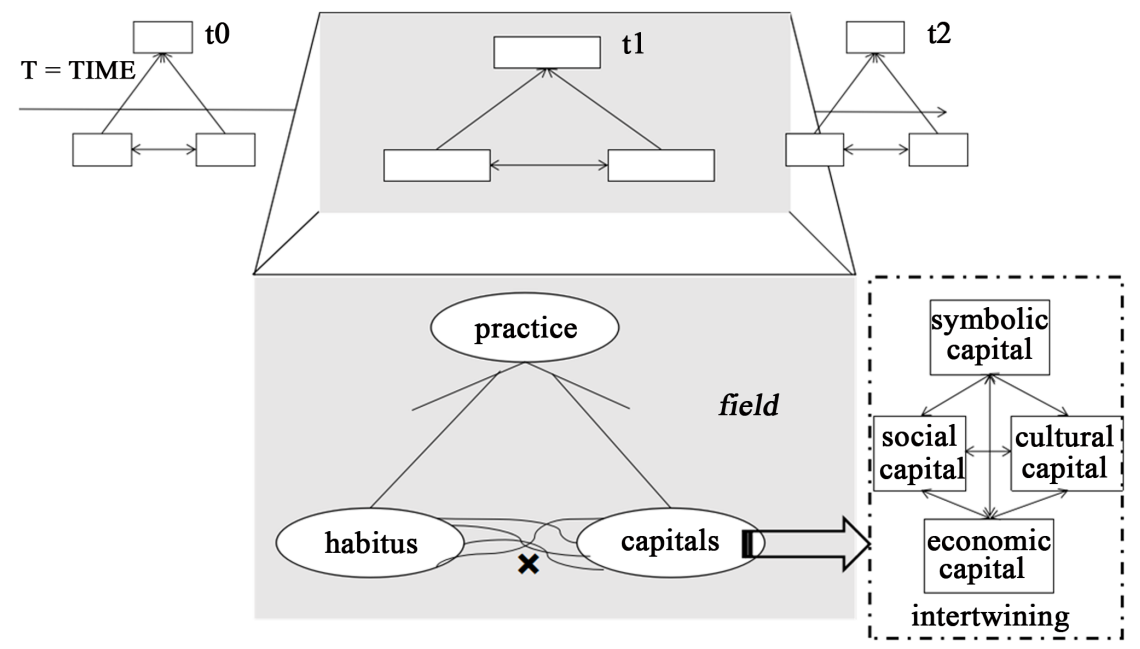

Figure 2. The structural logic of Bourdieu's practice theory. 
individual consciousness, habitus will naturally go to command and mobilize the individual and collective behavior direction and give a variety of social behavior with a specific meaning. Therefore, habitus has become the spiritual originate of social behavior, the way of life, the life style, the behavior rule.

Bourdieu's concept of capital is different with Marx and the traditional economics. He expanded it greatly and applied it to the fields of culture, society and so on. Thus he divided the capital into four types: economic capital, cultural capital, social capital and symbolic capital. Economic capital is the concept of capital in economic sense, it means "the money and material information that can be used to produce goods and services" [18]. Cultural capital is "informal interpersonal skills, habits, attitudes, language, tastes, educational level, and life style", and is "the use of different educational activities to transfer cultural goods". Bourdieu's cultural capital is divided into three main forms: 1) the concrete state, with a mental and physical endurance of the "character"; 2) the objective state, in the form of cultural goods, including books, dictionaries, tools, etc.; 3) the system state, mainly reflected in the identification of educational qualifications [19]. Social capital is a social resources and wealth by possessing the sustained social relational network. The capacity of social capital depends on the network range mobilized by social actors and the total capital held by each member they can contact in the network. Symbolic capital represents the individual's honor and reputation, and it has a legal effect, which can give the recognized person the social status [20].

These four capitals can transform into each other (see the Figure 3). Bourdieu think the process that all kinds of capitals transform into the symbolic capital, is the process that all of them are given the symbolic structure in the symbolic practice.

Bourdieu defines "field" as a structured social space, but also a configuration or network of relations with a specific distribution of power [21]. Bourdieu shows that interactions between people and their social structures must be explained in relation to the social space where such interactions occur. Agents' actions are governed by a set of social relations in concrete situations [22]. Bourdieu treats the field as a "battlefield" [23], where agents accumulate their economic capital, social capital, cultural capital and symbolic capital, they complete

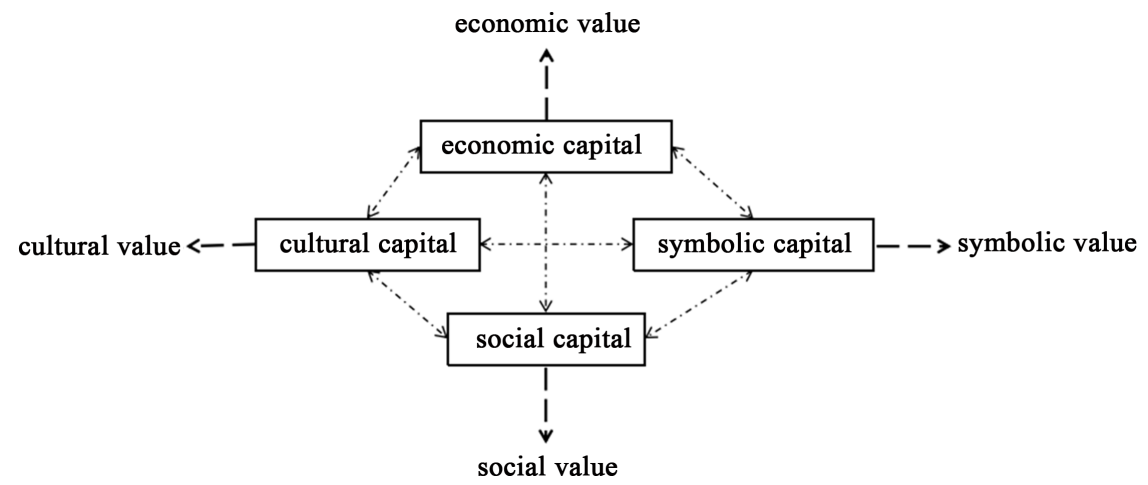

Figure 3. The mutual transformation of the four capital. 
for positions and prizes within fields. Bourdieu uses the "battlefield" to show how social actions play out, how agents' status is determined by the above four kinds of capital. Thus agents' actions are structured by the accumulation of the above four kinds of capital and their own habitus in the field.

For the agents in the field, the important problem is not only how much capital they have now, but how to face the relational network among the agents, how to grasp the capital trend of the agents in different social status, how to mobilize the capital in the hands of agents.

\subsection{How to Take Ethnographic and Fieldwork Method?}

The concepts above are thus "thinking tools" for Bourdieu's ethnographic method [24]. Bourdieu suggested three guiding principles: 1) The construction of the research object; 2) Engaging in a three-level approach to studying the field;

3) Engaging in participant objectivation [13].

The first principle guides us to construct a feasible but significant research object: what's the path of rural bank's transformation.

The second principle: At level one, we look at field relationships in relation to other fields within the broader field of rural bank's transformation. We find that the field of rural bank's transformation consisted of three inherent sub-fields: a) the field of politics, b) the field of economics, and c) the field of daily life (education, medical health etc.). This guidance helps us to recognize that mediating field and power relations operated as this mediation occurred. At level two, we position the above fields and their actors in the broader field of rural bank's transformation, and we recognize a particular form of transforming mechanism through which capitals(economic, social, cultural and symbolic) are allocated. This can help us to map out the structures occupied by politicians, merchants and villagers. At level three, we uncover the personal trajectories of individuals to understand how their habitus interacted with this field structure and how the structural logic of the field is embodied in their daily lives. Here, we analyze the way the people talk, walk, study, shop, hospitalize, eat, etc. We thus understand that habitus has changed, and it directs and positions individuals in the field in terms of the capital volumes and compositions they possess. This also help us to understand whether or not their habitus resonates with the structural logic of the field.

The third principle: participant engagements in the field provide a thorough understanding of how the interaction between habitus and field create a specific set of circumstances where "rare" capital won positions over the common.

To fulfill these conditions, we followed the case of the Wuwei Rural Bank's Transformation for 2 years and undertook the survey in 21 towns throughout the Wuwei country by communicating with the villagers for twice, the first investigation took place in October to November 2013 and the second took place in November to December 2015. For most of these period, we were on site in the bank and the villages for fulltime and stayed in the home of the mayor of a village for two weeks. Thirty-four in-depth interviews were conducted, involving 
the Wuwei Rural Bank's managers and common staffs, the mayors of 21 towns, convenience stores staffs, school principals, clinic employees and many villagers. These divergent actors carried their own habitus drawn from their structural logics of respective sub-fields and the broader field. Each actor was interviewed individually at least once, some several times, in order to gauge the nature of their daily lives through exploring issues emerging from previous discussions or raised by other people.

\section{The Transformation Practice of the Wuwei Rural Bank}

Wuwei County is affiliated to Wuhu City, Anhui Province, located in the central and southern part of Anhui Province, the north shore of the Yangtze River. Landform of Wuwei County is "mountains stay in the northwest and water ring in the southeast", mainly is the plain and hilly areas. Wuwei Country belongs to the subtropical monsoon climate, annual rainfall variation, frequent drought. The natural environment restricted the development of economy in the past. According to our research, Wuwei was one of the top ten poverty countries in China.

The recent census results show that most of the villagers are over 50 years old, and all the others go out to work or study. Because of the Chinese feudal culture and having no education, these left people didn't participate in the banking business, including savings and loans in banks, especially the rural banks. So the Wuwei Rural Bank was faced with serious problems of survival and development.

In order to understand the rural market conditions and the villagers, we did the first survey three years ago and took twenty-four interviews with the local villagers and the bank employees. The local villagers said that they didn't want to save their money in rural banks, because they were worried about the risks of rural banks and it was not convenient to save money in banks: they needed to take several hours to go to the town to handle the banking business. So they would like to save the cash in hands. When talking about bank loan, all of them didn't want to borrow money from rural banks, the reasons were as follows: firstly, the high loan interest made them to borrow money from friends and relatives; secondly, some villagers wanted to get bank loan, but gave up in the end because they couldn't meet the conditions of bank loans; thirdly, because the bank outlets were very few, they can only spend a long time to go to the town for the loan business. The Wuwei Rural Bank's business model was as shown in Figure 4 at that time.

The above description is just a phenomenon. In order to solve the problems of the Wuwei Rural Bank, we need to explore the nature of the villagers, and make a deep excavation from the origin. We found the practice theory of Bourdieu at last, because the three key concepts (field, habitus and capital) can help us to explain this phenomenon and be a tool for us to solve related problems. In the field the Wuwei Rural Bank involves, the habitus of villagers plays an central role at this stage. According to Bourdieu, habitus is produced in the life throughout 


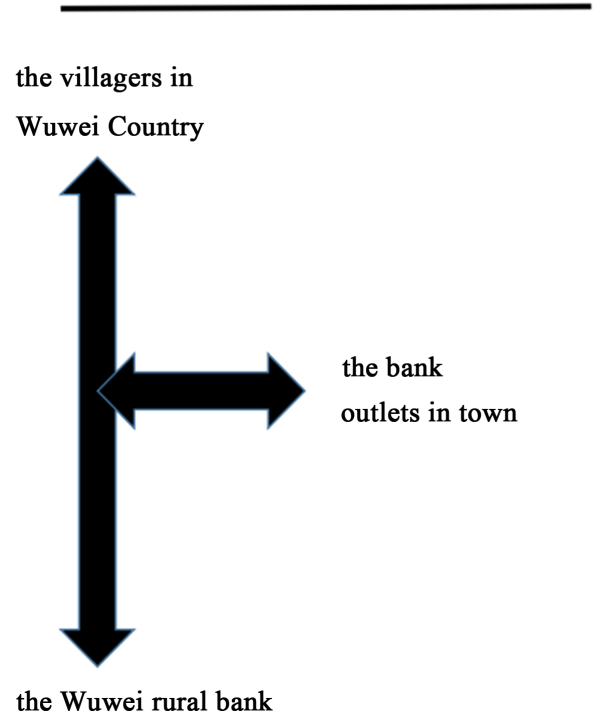

Figure 4. The Wuwei Rural Bank's business model before 2013.

history and acquired by the agents. Then habitus produces practices and representations available. And habitus implies a "sense of one's place", but also a "sense of the place of others" [20]. The Wuwei villagers are lack of education, they live in here for a long time and deeply influenced by the Chinese feudal culture that is backward. Then their habitus were shaped in the context, this is inherent and structured in their body and can't change easily.

Previous studies always treat the villagers and the bank as discrete entities based on the typical dichotomy. They don't treat them in a relational thinking, so they cannot solve the problem from the origin. We should look for other ways to solve the problem. Strengthen the interaction between the bank and the villagers, so the bank can find out the villagers' credit conditions clearly and reduce the operational risk, on the other hand, the villagers can change their habitus gradually and handle savings, loans and other banking business conviently. So the Wuwei Rural Bank adopted the practice theory of Bourdieu based on relational thinking. First, the Wuwei Rural Bank analyzed the different capitals of the villagers and organizations or groups in the field in order to make full use of the key nodes who have much social/symbolic capital in the network of the Wuwei country and towns. Through a month of investigation and research, the Wuwei Rural Bank found that governments had a large number of symbolic capital, social capital, cultural capital and economic capital, the convenience stores had strong economic and social capital, the schools had a rich cultural and social capital, the hospitals had a lot of social capitals.

The former said that the villagers didn't want to take banking business because of few bank outlets, risk and difficult to loan. So the Wuwei Rural Bank put the ATM machines in the room of these five categories of villagers, teach them how to use them and make them be the banking business agent. Then the Wuwei Rural Bank put forward a model of Bank-Government mixture, and it 
not only provides banking services, but also provides other services with the support of government and other groups, such as intelligent logistics, rural e-commerce, rural medical and education \& training, forming and service network of the " 1 "+ "N", see as Figure 5 shows.

In the model of Bank-Government mixture, symbolic capital and social capital play an important role. The symbolic capital is the highest form of the capital, and it refers to the legitimate bases for claiming esteem, honor, prestige, respect and recognition in a given field [23]. The credibility and honor of government and the recognition of some groups (the convenience stores, the schools, the hospitals etc.) are symbolic capital. And all of these groups have much social capitals, who interact with a large number of people every day. This symbolic capital and social capital eliminate the risks that the villagers perceived and they also provide convenience for the villagers.

When we came back to the Wuwei Country last year, we were surprised by the Wuwei Rural Bank's development. ATM machines are spread across every village, and the Wuwei Rural Bank is recognized and trusted by local villagers. And the habitus of the villagers is changed now.

The strategic transformation of rural banks is bound to rebuild the villagers habitus, and this process is filled with all sorts of difficulties and boycott. The Wuwei Rural Bank's transformation practice reveals a process, it changed the old habitus of villagers through the mutual construction of capitals especially the symbolic capital and the social capital, and built the new habitus with the interaction of multi agents. It opened the black box of the conflict and coordination of strategic choices of rural banks, see as Figure 6 shows.

\section{Conclusion}

This paper provides a new perspective for the transformation path of rural banks through the case of the Wuwei Rural Bank. By fully understanding the Bourdieu's practice theory, using the capital especially symbolic capital and social capital to build a model of "Bank-Government mixture" to reconstruct the villagers' habi-

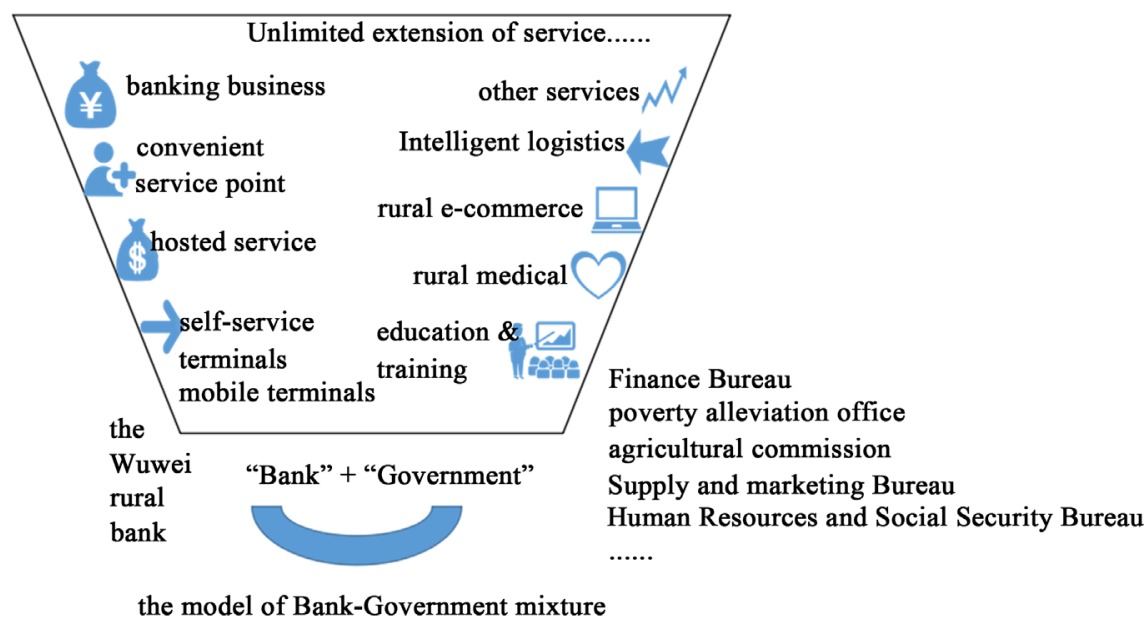

Figure 5. The model of Bank-Government mixture in the Wuwei Rural Bank. 


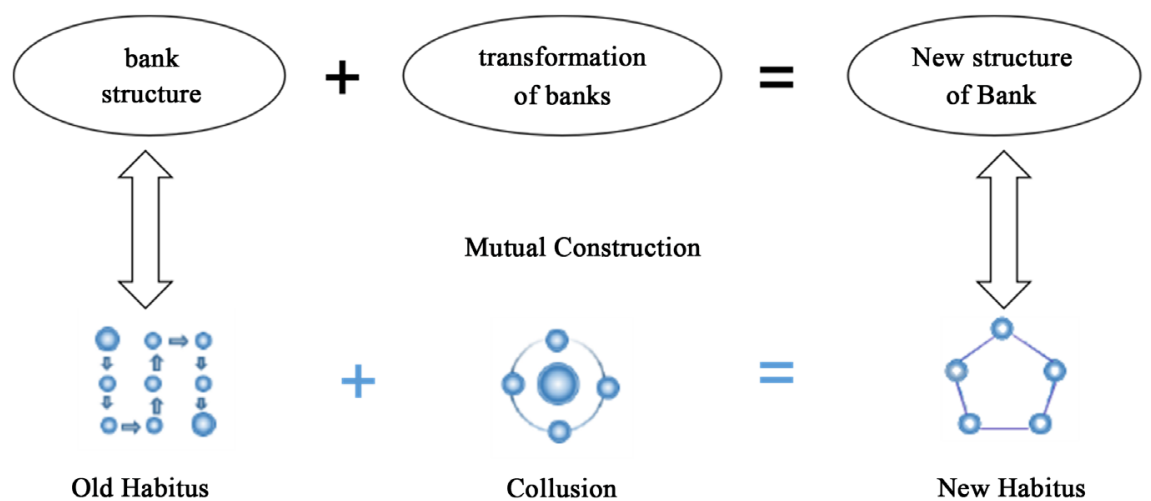

Figure 6. The habitus change in the transformation of the Wuwei Rural Bank.

tus, and extending the field of pure banking business into the field of social finance, the Wuwei Rural Bank realizes the successful thorough transformation, and now becomes the partner of villagers to go prosperous and powerful. The successful transformation of the Wuwei Rural Bank indicates that we should change the agents' habitus according to the objective structure, and capital especially symbolic capital and social capital plays an important role in the structure.

\section{Financed}

The research is financed by Enterprise Development Research Institute of Jinan University: "Study on Dynamical Mechanism, Strategic Operation Strategy of Enterprise Transformation" 2014ZD002, Jinan University-Hande Information based on Oracle/SAP ERP business operations practice education base, Guangdong Finance Society 2016-2017 major decision-making consulting research project "financial support Guangdong rural entrepreneurship research-based on the four capitals and 3P model perspective".

\section{References}

[1] Li, M., Luo, H. and Yi, R. (2016) The Development of Village Banks, System Reform and Path Selection of China. Reform of Economic System, 4, 18-24.

[2] Haiyan, Z. and Yu, C. (2016) Analysis on the Present Situation and Countermeasures of the Development of Rural Bank. People's Tribune, 2, 76-78.

[3] Gao, Y. (2016) Research on Operational Efficiency and Influencing Factors of Rural Banks in China-Based on the Analysis of Provincial Panel Data. Review of Investment Studies, 2, 78-86.

[4] Zhang, Y. (2016) Research on the Sustainable Development of Rural Banks under the Background of New Urbanization. Communication of Finance and Accounting, 20, 18-21.

[5] Li, R. and Tan, C. (2015) Enhance the Credibility of Rural Banks. China Finance, 9, 101-101.

[6] Wang, J., Yu, Y. and Li, F. (2014) Problems and Countermeasures in the Development of Rural Banks in China. Economic Review, 6, 107-110.

[7] Wang, H., Luo, G. and Hong, H. (2016) Beyond Socio-Materiality and Sense-Making: Planting Symbolic Power and Critical Realism into Strategy-As-Practice Logic. 
Open Journal of Business \& Management, 4, 177-187. https://doi.org/10.4236/ojbm.2016.42020

[8] Sieweke, J. (2011) The Dissemination of Pierre Bourdieu's Theory of Practice in Management and Organisation Studies. SSRN Electronic Journal, 1, Article ID: 1961139. https://doi.org/10.2139/ssrn.1961139

[9] Baxter, J. and Chua, W.F. (2008) Becoming the Chief Financial Officer of an Organisation: Experimenting with Bourdieu's Practice Theory. Social Science Electronic Publishing, 19, 212-230.

[10] Everett, J. (2002) Organizational Research and the Praxeology of Pierre Bourdieu. Organizational Research Methods, 5, 56-80. https://doi.org/10.1177/1094428102051005

[11] Li, D.W. (2014) International Experience, Risk Analysis and Supervision of the Internet Finance. Journal of Jilin Financial Research, 4, 35-39.

[12] Orlikowski, W.J. and Scott, S.V. (2015) The Algorithm and the Crowd: Considering the Materiality of Service Innovation. Management Information Systems Quarterly, 39, 201-216.

[13] Jayasinghe, K. and Wickramasinghe, D. (2011) Power over Empowerment: Encountering Development Accounting in a Sri Lankan Fishing Village. Critical Perspectives on Accounting, 22, 396-414. https://doi.org/10.1016/j.cpa.2010.12.008

[14] Bourdieu, P. (1990) In Other Words: Essays towards a Reflexive Sociology. Polity Press, Cambridge.

[15] Decoteau, C.L. (2016) The AART of Ethnography: A Critical Realist Explanatory Research Model. Journal for the Theory of Social Behaviour, 47, 58-82. https://doi.org/10.1111/jtsb.12107

[16] Bourdieu, P. (1985) The Social Space and the Genesis of Groups. Theory \& Society, 14, 723-744. https://doi.org/10.1007/BF00174048

[17] Fayard, A.L. and Weeks, J. (2014) Affordances for Practice. Information \& Organization, 24, 236-249. https://doi.org/10.1016/j.infoandorg.2014.10.001

[18] Bourdieu, P. (1977) Outline of a Theory of Practice. Cambridge University Press, Cambridge. https://doi.org/10.1017/CBO9780511812507

[19] Bourdieu, P. (1986) The Forms of Capital, Blackwell Publishers Ltd, Hoboken.

[20] Bourdieu, P. (1989) Social Space and Symbolic Power. Sociological Theory, 7, 14-25. https://doi.org/10.2307/202060

[21] Bourdieu, P. (2005) The Political Field, the Social Science Field, and the Journalistic Field. In: Benson, R. and Neveu, E., Eds., Bourdieu and the Journalistic Field, Polity Press, Cambridge.

[22] Bourdieu, P. (1993) Sociology in Question: Theory, Culture, and Society (NetLibrary, Incorporated).

[23] Bourdieu, P. and Wacquant, L. (1992) An Invitation to Reflexive Sociology. University of Chicago Press, Chicago.

[24] Grenfell, M. (2008) Postscript: Methodological Principles. Key Concepts, Pierre Bourdieu, 219-227. 
Submit or recommend next manuscript to SCIRP and we will provide best service for you:

Accepting pre-submission inquiries through Email, Facebook, LinkedIn, Twitter, etc. A wide selection of journals (inclusive of 9 subjects, more than 200 journals)

Providing 24-hour high-quality service

User-friendly online submission system

Fair and swift peer-review system

Efficient typesetting and proofreading procedure

Display of the result of downloads and visits, as well as the number of cited articles Maximum dissemination of your research work

Submit your manuscript at: http://papersubmission.scirp.org/

Or contact jssm@scirp.org 